\title{
THE MIS COURSE IN THE MBA CURRICULUM: CURRENT PRACTICE AND FUTURE DIRECTIONS
}

\author{
Fred K. Augustine, Jr, Stetson University, USA, fauguti@stetson.edu \\ Ted Surynt, Stetson University, USA, tsurynt@stetson.edu
}

\begin{abstract}
The MBA curriculum is the subject of considerable research and discussion. This includes frequent criticism of the value of an MBA degree. This criticism typically centers on either a lack of relevancy to current business, economic or social conditions or to the claim of business practitioners that MBA graduates are lacking in preparation for the demands of modern business careers. One area of specific interest is that of MIS and how this topic and skills area is represented in MBA degree programs. This paper examines the current state of the MBA curriculum by specifically asking the questions, "To what degree is MIS represented in MBA curricula?" And "how are MIS courses operationalized at the MBA level?" To answer these questions, we have conducted a thorough search of over one thousand universities that offer MBA programs, to determine how and to what degree MIS is integrated into MBA curricula.
\end{abstract}

Keywords: MBA Curriculum, MIS, Information Systems and Information Technology

\section{INTRODUCTION}

In the period prior to the bursting of the dot.com bubble, the "solution" to the Y2K problem and the subsequent decline of the "tech stock" bull market; Information Technology was in a state of unprecedented growth not only in industry but also in the academic world. Subsequent economic events caused business leaders and academics to reexamine their expenditures on technology and to reassess its relevance in the university curriculum. In the academic world of business, such significant events can create major shifts in the prevailing curricular mindset. MBA programs, in particular, are often especially quick to react to changes in the business environment. Since the typical MBA program will offer some sort of Business Information Technology course, the availability of courses focusing on Information Technology or closely related topics (MIS, E-Business, etc.) should provide an indication of the degree to which Information Technology is considered to be an important element of an MBA curriculum.

Over the years, much has been written about the MBA curriculum. This includes frequent criticism of the value of an MBA degree [8, 4]. This criticism typically centers on either a lack of relevancy to current business, economic or social conditions or to the claim of business practitioners that MBA graduates are lacking in preparation for the demands of modern business careers. This criticism includes the specific topics and courses, such as the MBA MIS course, that appear in MBA programs. In order to address the issue of the adequacy of the coverage of MIS in the MBA degree, it is first necessary to understand the state of the MBA degree as it is currently implemented. In order to do so, we have conducted a thorough examination of the curricula of over one thousand universities that offer MBA programs, to determine the degree to which a number of topics are integrated into MBA curricula.

\section{A Brief History of the MBA Degree}

The MBA degree has a history that spans over a century. The first US Business School was the University of Pennsylvania's Wharton Business School, founded in 1881. The Tuck School of Business at Dartmouth College (founded in the year 1900) offered the first business graduate degree, then known as the Master of Commerce. A few years later, in 1908, the Harvard University Graduate School of Business offered the first MBA degree.

Additional milestones in the history of the MBA degree include the first executive MBA program, offered by the school of business at the University of Chicago in 1943; the first MBA degree offered outside of the United States, by the Richard Ivey School of Business at the University of Western Ontario in 1950; and the first European MBA offered by INSEAD (Institut Europeen d' Administration des Affairs).

By the late 1950s considerable criticism of the MBA degree had begun to emerge. The year 1959 was a watershed year for criticism of MBA programs. In 1959 a report entitled "Higher Education for Business" was written by Robert Aaron Gordon and James Edwin Howell, a pair of Economists. This report, known as the Gordon - Howell 


\section{Issues in Information Systems \\ Volume 14, Issue 1, pp.339-346, 2013}

report was commissioned by the Ford foundation. The Gordon - Howell report criticized the current state of implementation of MBA programs. Among the criticisms put forth in this report were that MBA programs were characterized by narrow, simple and weak curricula. The report likened MBA curricula to that of trade schools. In addition the report criticized the caliber of faculty and students in these programs. In concluding the report called for more research and less consulting by MBA faculty. The report also called for improved regulation and greater emphasis on theory and analysis along with more coverage interestingly enough of ethics. Also in 1959, the Carnegie foundation commissioned a report entitled "The Education of American Businessman: A Study of University - College Programs in Business Administration". This report was written by Frank Pierson, a professor of Economics at Swarthmore College (a liberal arts institution that does not have a business school). The Carnegie foundation report also criticized the standards of schools business and argued that programs were being developed too hastily [6].

More recent criticisms of the MBA degree have centered on the ethical behavior (or lack thereof) of business practitioners who hold MBA degrees and the adherence of MBA granting institutions to the scientific model. Bennis and O'Toole [4] describe this problem:

"This scientific model, as we call it, is predicated on the faulty assumption that business is an academic discipline like chemistry or geology. In fact, business is a profession, akin to medicine and the law, and business schools are professional schools - or should be. Like other professions, business calls upon the work of many academic disciplines. For medicine, those disciplines include biology, chemistry, and psychology; for business they include mathematics, economics, psychology, philosophy, and physiology. The distinction between a profession and the academic discipline is crucial. In our view, no curricula reforms will work until the scientific model is replaced by a more appropriate model rigid in the special requirements of a profession.

Thus, the more recent criticism of the MBA degree comes almost full circle from those criticisms put forward in 1959. The MBA is seen as a degree is curriculum is less than relevant to practitioners and is based on an academic model that is inappropriate for an academic discipline that is actually a profession.

\section{Curriculum Standards}

An institution that is intimately involved with the evolution of the MBA curriculum is the Association to Advance Collegiate Schools of Business (AACCSB). As the top level accrediting body, internationally, for business programs, the AACCSB as has published standards for both undergraduate and graduate business curricula. AACSB standard 15 (Management of Curriculum) requirements state that (the standard):

"does not normally require any specific courses" and that "normally the curriculum management process will result in undergraduate and master's level general management degree programs that will include learning experiences in such management specific knowledge and skills areas as:

- Ethical and legal responsibilities in organizations and society

- Financial theories, analysis, reporting, and markets

- Creation of value through the integrated production and distribution of goods, services, and information

- Group and individual dynamics in organizations

- Statistical data analysis and management science ...

- Information technologies ...

- Domestic and global economic environments of organizations Other management-specific knowledge and abilities as identified by the school [1]

It is important to note that "information technologies" represents one of the core knowledge requirements articulated in the AACSB standards. Although the standard does not require specific courses, the normal means of implementation of the specific knowledge and skill areas within an MBA curriculum is to include them as individual courses or as a part of an individual course. 


\section{The MBA Curriculum Value Chain Analysis Model}

Although a considerable degree of diversity exists in the implementation of the degree, there are certain essential commonalities. One of these is the existence of a dichotomy which features courses which can be classified as being either primary or supporting. This dichotomy is modeled after the classification of business functions in Value Chain Analysis as primary or supporting [11]. In this case, the business functions are replaced by the academic disciplines which constitute Schools and Colleges of Business. While there is no perfect agreement as to which business disciplines constitute primary activities and which are supporting we have chosen to classify the disciplines as follows:

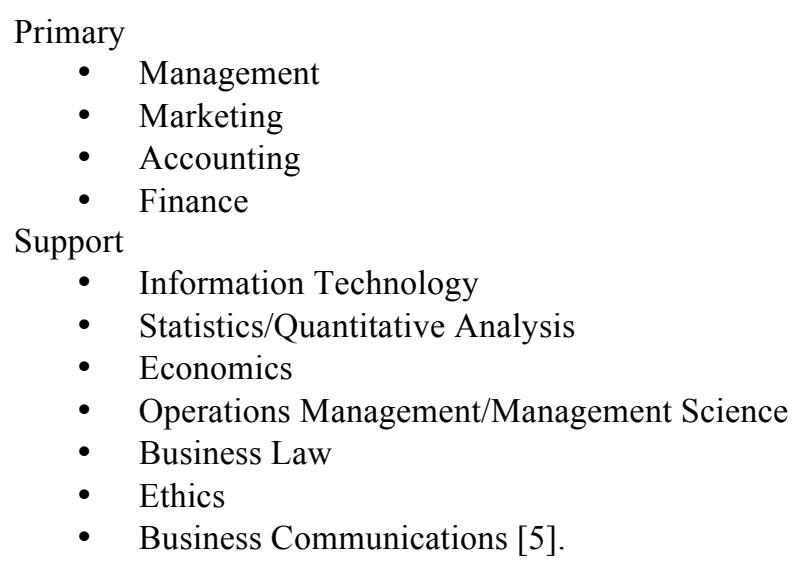

So while Information Technology is not classified as a "primary" discipline, it is listed among the important knowledge areas defined as support disciplines.

\section{INFORMATION TECHNOLOGY VS INFORMATION SYSTEMS}

Before moving on to discuss the details of the research, it is important to make clear the distinction between information systems (IS) and information technology (IT). Although often used interchangeably, the meaning of these two terms has been diverging for a number of years. As early as 2005, it was noted that the roles of IS professionals were significantly different than the roles of their IT counterparts [14]. It is generally agreed that the creation and maintenance of better and more efficient computing platforms and networks is the purview of IT. This places them closer to the traditional role of our computer science colleagues. Creating the agile infrastructure that allows an organization to innovate on top of existing processes is the name of the game for IT. IS professionals, on the other hand, are charged with taking this technical platform and nurturing the process innovations that allow an organization to create a sustainable competitive advantage. Their skill sets must contain both technical savvy and business savvy. They must be comfortable with the latest technologies but must also have the functional, analytic, team building, and organizational skills that allow them be successful within the business context [10].

This distinction between IS and IT has been addressed in academia as well. Both IS and IT model curricula, defining undergraduate bodies of knowledge for the respective disciplines, have been developed. The Association for Computing Machinery (www.acm.org) and the Association for Information Systems (www.aisnet.org) have produced a number of suggested curriculum revisions for IS undergraduate programs over the years. Their most recent effort was published in 2010 [17]. A separate document outlining curriculum suggestions for the undergraduate IT side of the house was developed in 2008 (IT2008). As you would expect, there is a good deal of overlap between the two curricula. The IT curriculum however is far mover heavily focused on the technology itself, whereas the IS curriculum focuses more heavily on technology issues within the organizational context. For the purposes of this research, we have chosen to use the term MIS (Management Information Systems) as an aggregate term which incorporates IS (Information Systems) and IT (Information Technology).

\section{The Evolution of the MIS Course in the MBA Curriculum}




\section{Issues in Information Systems \\ Volume 14, Issue 1, pp.339-346, 2013}

Over time, the focus of the MIS knowledge area in the MBA curriculum has changed as MBA and MIS curricula have evolved. This evolution has been reflected by the choices made by MBA programs as to the theme and content of the course or courses chosen to represent the MIS knowledge area in their respective curricula.

\section{Categorization of MIS Courses}

Additional analysis of the data collected in the survey was conducted relating specifically to the MIS courses included in the identified MBA programs. Specifically, the name of each MBA course was collected and categorized. A total of 17 categories were developed. These categories classified the MIS course based on the course content. The categorizations were based on common MIS topic area names. In some cases, it was impossible to categorize a course based on its name alone. This occurred in situations where the name was either ambiguous or contained multiple topic designators. In these cases the courses were placed in categories based on an examination of the catalog description of the course. Table 1 displays the 17 MIS course categories along with the number and percentage of courses which fell into each category.

Table 1. Categories of MIS Courses

\begin{tabular}{|l|c|c|}
\hline Category Name & Number of Courses & \% of Total \\
\hline MIS & 145 & $38.98 \%$ \\
\hline Management of Technology/IS & 68 & $18.28 \%$ \\
\hline IT & 38 & $10.22 \%$ \\
\hline Hybrid OM/DS & 24 & $6.45 \%$ \\
\hline Strategic IS & 22 & $5.91 \%$ \\
\hline Information Management & 14 & $3.76 \%$ \\
\hline E-Commerce/E-Business & 11 & $2.96 \%$ \\
\hline Information/Data Analysis & 9 & $2.42 \%$ \\
\hline Enterprise Systems & 8 & $2.15 \%$ \\
\hline Corporate IS & 7 & $1.88 \%$ \\
\hline DSS & 6 & $1.61 \%$ \\
\hline Modeling and Simulation & 6 & $1.61 \%$ \\
\hline Analytics/Business Intelligence & 5 & $1.34 \%$ \\
\hline Systems and Information Theory & 3 & $0.81 \%$ \\
\hline Communication Technologies/Networks & 3 & $0.81 \%$ \\
\hline Hybrid Other & 2 & $0.54 \%$ \\
\hline Systems Analysis & 1 & $0.27 \%$ \\
\hline Totals: & 372 & $100.00 \%$ \\
\hline
\end{tabular}

\section{RESEARCH METHODOLOGY}

Our current research is an extension of previous research into the current state of the MBA curriculum [13]. This research examined the degree to which supporting disciplines are represented in MBA curricula?" This research involved conducting a thorough search of 1062 universities to determine which offer MBA programs. In this dataset we found 628 schools that offered MBA degrees. Data was collected via the examination of the institutional web sites of the constituent universities and drilling down within these sites to obtain specific information about their academic programs. The current research extends this survey to focus on the role of the MIS course in the MBA. Specifically we have categorized the MIS courses offered as part of the curricula of each of the 628 MBA granting institutions included in the survey and examined the frequency that courses falling into each category are included in MBA programs of study. We have employed a variety of descriptive measures to explore the relationship existing 


\section{Issues in Information Systems \\ Volume 14, Issue 1, pp.339-346, 2013}

between the MIS course and the courses representing the support disciplines in the MBA curriculum and to define the prevailing norm in terms of the content of this course.

\section{RESULTS}

Table 2 details the basic results of the original curriculum survey. This table shows the number of courses offered in each of the eight academic support areas. The following abbreviations are used to represent the supporting disciplines.

- $\quad$ MIS - Information Technology, MIS, Database, Business Intelligence

- OPS - Operations Management, Management Science, Decision Analysis

- $\quad$ STA - Statistics, Research Methods, Quantitative Analysis

- ECO - Economics

- LAW - Legal, Business Law

- $\quad$ ETH -- Ethics

- $\quad$ INT - International, Global

- $\mathrm{COM}-$ Communications, Managerial Communications, Presentations

Table 2. Summary Results

\begin{tabular}{|l|c|c|c|c|c|c|c|c|c|}
\hline & MBA & MIS & OPS & STA & ECO & LAW & ETH & INT & COM \\
\hline Count & 628 & 380 & 453 & 280 & 341 & 114 & 153 & 121 & 48 \\
\hline Total & & $4721 / 2$ & 578 & $3521 / 2$ & $4499^{1 / 2}$ & $143 \frac{1}{2}$ & $201 \frac{1}{2}$ & $1671 / 2$ & $633^{1 / 2}$ \\
\hline $\begin{array}{c}\% \\
\text { Included }\end{array}$ & $61 \%$ & $72 \%$ & $45 \%$ & $54 \%$ & $18 \%$ & $24 \%$ & $19 \%$ & $8 \%$ \\
\hline $\begin{array}{c}\% \\
\text { Multiple } \\
\text { Courses }\end{array}$ & $6.1 \%$ & $13.7 \%$ & $4.3 \%$ & $11.4 \%$ & $0 \%$ & $1.3 \%$ & $8.3 \%$ & $4.2 \%$ \\
\hline
\end{tabular}

In addition the chart displays the total number of courses offered, the percentage of programs that include these courses, and the percentage of programs that include multiple courses in each support area. Fractional values for course totals occur based on the inclusion of courses which represent more than one of the support disciplines, for example, numerous institutions offer a course titled Ethics and Law.

MIS courses were found to be components of MBA degrees offered by 380 of the 628 MBA granting universities surveyed. Not surprisingly, this represents the second highest rate of inclusion, behind only Operations/Management Science ( $72 \%$ to $61 \%$ ). MIS ranked $4^{\text {th }}$ out of 8 in terms of the percentage of multiple inclusions (more than one course from a discipline included in an MBA curriculum). An important result of this survey was the revelation of the number of MBA programs that include no coverage in one or more of the supporting disciplines. These results are summarized below.

Table 3. No Coverage in Curriculum

\begin{tabular}{|l|c|c|c|c|c|c|c|c|}
\hline & MIS & OPS & STA & ECO & LAW & ETH & INT & COM \\
\hline Percentage & $39 \%$ & $28 \%$ & $55 \%$ & $46 \%$ & $82 \%$ & $76 \%$ & $81 \%$ & $92 \%$ \\
\hline
\end{tabular}

Again, MIS ranks second behind Operations/Management Science (28\% vs. $39 \%$ ). What is surprising about these results is an MIS course would be excluded from any MBA curriculum. A possible explanation would be that the general popularity of MIS courses within MBA programs has decreased along with the popularity of MIS degrees since 2001. In addition, MBA programs have, in aggregate, experienced approximately a $20 \%$ decline in enrollment when compared with their historical highs which occurred prior to the 2008 financial crisis and recession. In response, many institutions have decreased the number of courses or credit hours required to receive an MBA degree. Unfortunately, as this study is not longitudinal, we cannot offer precise information on the magnitude of any of these changes. 


\section{Issues in Information Systems \\ Volume 14, Issue 1, pp.339-346, 2013}

\section{Analysis}

A correlation analysis was performed on the frequency data is shown in Table 4. Specifically, we have examined the relationship between the inclusion of the various supporting discipline courses found in the MBA programs referenced in the survey as well as the number of courses which comprise each MBA curricula. T statistics were calculated for the correlations between the inclusion of the MIS course and of each of the other seven supporting discipline courses. The correlation matrix is shown below:

\begin{tabular}{|l|c|c|c|c|c|c|c|c|c|c|}
\hline \multicolumn{10}{|c|}{ Table 4. Correlation Analysis } \\
\hline & MIS & OPS & STA & ECO & LAW & ETH & INT & COM & Courses & T Values \\
\hline MIS & 1 & & & & & & & & & \\
\hline OPS & 0.12 & 1 & & & & & & & & $2.89^{*}$ \\
\hline STA & 0.08 & 0.13 & 1 & & & & & & & $1.93^{*}$ \\
\hline ECO & -0.05 & 0.19 & 0.26 & 1 & & & & & & -1.18 \\
\hline LAW & -0.01 & 0.15 & 0.14 & 0.26 & 1 & & & & & -0.20 \\
\hline ETH & -0.03 & 0.06 & 0.06 & 0.24 & 0.37 & 1 & & & & -0.67 \\
\hline INT & -0.02 & 0.12 & 0.10 & 0.12 & 0.26 & 0.29 & 1 & & & -0.39 \\
\hline COM & -0.03 & 0.11 & 0.11 & 0.22 & 0.14 & 0.25 & 0.17 & 1 & & -0.74 \\
\hline Courses & 0.05 & 0.12 & 0.15 & 0.03 & 0.01 & -0.04 & -0.05 & 0.03 & 1 & \\
\hline
\end{tabular}

* Significant at the .01 level; ** Significant at the .05 level

The only correlations with the MIS course that are statistically significant are for the Operations Management (OPS) and Statistics (STA) courses. Although these correlations are statistically significant, indicating that we can reject the hypothesis that the correlations between these courses in the MBA curriculum are equal to zero, the correlations are very low (12\% and $8 \%$ respectively). The fact that there is some relationship between the inclusion of the MIS, $\mathrm{POM}$, and Statistics courses in MBA curricula is not surprising given the fact that some MBA curricula tend to emphasize the more quantitative or technologically oriented courses. The fact that these correlations are so low (while being statistically significant) may simply be an indication of the considerable diversity in MBA curricula, in spite of the AACSB standards which require specific coverage of each of these topic areas.

\section{Future Directions}

The categorizations shown in Table 3 highlight the considerable diversity with which MBA programs implement the AACSB Standard 15 curriculum requirements. In spite of this diversity, over $67 \%$ of MIS courses included in MBA curricula fall into one of three of the seventeen categories (MIS, IT, and Management of IS). This indicates at least some agreement among the various degree granting institutions. The inclusion of MIS courses in MBA curriculum tends to be a reflection of current trends in MIS curricula at both the graduate and undergraduate level. At various points of time in the past, topics areas such as MIS, Decision Support Systems (DSS) and Electronic Commerce have gained significant popularity and have attained significant levels of representation in the MBA curricula.

This lack of consensus can be largely attributed to the fact the MIS discipline has undergone dramatic and consistent change. It would be difficult to identify an academic program which has morphed over time as often as the technology major in business schools. Whether we call it Management Information Systems (MIS), Computer Information Systems (CIS), Business Information Systems (BIS), Information Systems (IS), E-Business Technology (EBT), Information Technology (IT) or something else, there is no doubt that both the name and the curriculum of this major has changed often over the past twenty or so years [7,9]. Of course part of this is due to the nature of the curriculum itself. Mature business technologies ultimately become obsolete. Technical innovation creates new areas of interest and opportunity that define new skills that must be mastered by our graduates. The focus of business technology expertise today is maturing beyond the "purely technical". At the business unit level, MIS must address 


\section{Issues in Information Systems \\ Volume 14, Issue 1, pp.339-346, 2013}

the tactical side of solving specific business problems or exploiting specific business opportunities. At the corporate

level, MIS is becoming more centered on supporting and being supported by the overall strategic plan.

Business schools have the wherewithal and the opportunity to provide graduates with the skills that bring ever greater value to the organization in its struggle for a sustainable strategic competitive advantage (Zweig, 2006). This is typically accomplished via the vehicle of the curriculum. At the MBA level, curriculum design must focus on these objectives and at the same time, adapt in response to valid criticisms of the MBA curriculum. Thus, new directions for the future must the relatively recent increase in interest in providing a solid quantitative and technological foundation for MBA degree recipients. This is also consistent with criticisms of MBA curricula focusing too heavily on "the numbers" and not heavily enough on what "the numbers" mean. One area where all of these objectives can be met is Business Analysis. There is a relatively new movement in the arena of MIS curriculum development which focuses on producing graduates who are trained as Business Analysts. MIS curricula which are structured around this objective seek to combine traditional MIS skills with those relating to business analytics and business intelligence [16]. The case for this new professional is being made emphatically on the practitioner side. A recent Computerworld article proclaimed "(organizations) are finding that they need professionals with unique skills... But these professionals aren't strictly IT oriented, nor can they be business specialists who don't have deep technical acumen. Rather, this is an emerging hybrid position that requires someone who can manage data, handle software, ask the right business questions and present results" [12]. To meet the emerging requirements of working with "big data" and using this data to gain competitive advantage, MBA programs must update their MIS focus to meet the changing needs of the workplace.

\section{FURTHER RESEARCH}

Although this research provides a thorough assessment of the frequency of occurrence of the MIS course in MBA curricula, it does not address another important area of potential interest for future research. This is the qualifications and or specializations of faculty teaching the MBA MIS course. Information about this topic could be of great interest, especially in terms of the field qualifications of those who are routinely tasked with teaching this course in MBA programs. The gathering of this information would go beyond the current methodology (examination of university web sites) and require a survey of MBA granting institutions.

\section{CONCLUSIONS}

Many of the results reported above are expected, such as the high level of inclusion of MIS courses in MBA curricula. This is consistent with a number of environmental forces which work to shape curriculum development. First, there is an explicit requirement in the current AACSB standards which mandates that master's level general management degree programs that will include a specific group of management specific knowledge and skills areas, one of which in "information technologies" [1]. Second, recent criticisms of MBA curricula militate towards, not away from the inclusion of topics and skill areas like MIS which can provide a greater level of quantitative and technical expertise to graduates of these programs. Unfortunately, the current focus of MBA courses is largely (over $70 \%$ ) on more traditional topic and skill areas (MIS, IT and Technology Management). This runs contrary to the contemporaneous need for graduates who possess business and analytic skills. This study does not answer the question, what is the emerging trend in MBA programs with respect to the content of the MIS courses that are part of the MBA curriculum. This fact highlights the need for a longitudinal study in this area.

\section{REFERENCES}

1. AACSB. (2010). Eligibility Procedures and Accreditation Standards for Business Accreditation, AACSB International - The Association to Advance Collegiate Schools of Business, Revised January 31, 2010.

2. Augustine, F. K., \& Surynt, T. J. (2001). E-Business in the Curriculum: An Examination of Current Practice and Organization. The E-Business Review, Vol 1, pp. 11-13, 2001.

3. Augustine, F. K., \& Surynt, T. J. (2013). Representation of Supporting Disciplines in the MBA Curriculum. Proceedings of the 14 $4^{\text {th }}$ Annual Conference of the Academy of Business Disciplines, pp. 61-67.

4. Bennis, W. and O'Toole, J. (2005). How Business Schools Lost Their Way, Harvard Business Review

5. Digital Commons. (2012). Disciplines: Introduction to Digital Commons Three-Tiered Taxonomy of Academic Disciplines, Digital Commons Reference Material and User Guides. 2012 
6. The More Things Change: A Seminal Critique of American Business Educations, Five Decades On, (2009), The Economist.

7. Gambill, S., Clark, J. \& Maier, J. (1999). CIS vs. MIS vs. ...: The Name Game, Journal of Computer Information Systems. 39(4), 22-25.

8. Gordon, R. A. \& Howell, J. E. (1959) Higher Education for Business. New York: Columbia University Press.

9. Kung, M., Yang, S. C. \& Zhang, Y. (2006). The Changing Information Systems (IS) Curriculum: A Survey of Undergraduate Programs in the United States. Journal of Education for Business. 8(6), 291-299.

10. Overby, S. (2006). How to Hook the Talent You Need. CIO, 40-54.

11. Porter, Michael E., Competitive Advantage. 1985, Ch. 1, pp. 11-15. The Free Press. New York.

12. Pratt, M. (2011). Wanted: BI Stars. Computerworld. September 12, 2011, 28-30.

13. Risi, K. (2005). MBA in Transition: Factors Driving Curricular Change, Doctoral Thesis, Drexel University

14. Shackelford, R., Cross, J., Davies, G., Impagliazzo, J., Kamali, R., LeBlanc, R., Lunt, B., McGettrick, A., Sloan, R., \& Topi, H. (2005). Computing Curricula 2005 - The Overview Report, ACM/IEEE Computer Society, 2005.

15. Srikant, M., Garvin, D., and Cullen, P. (2010). Rethinking the MBA: Business Education at the Crossroads, Harvard Business Press.

16. Surynt, T. J., Oliphant, G., and Augustine, F.K. (2012). Enriching the Undergraduate Information Systems Experience: Programs in Business Systems Analysis, Proceedings of the 2012 Academy of Business Education International Conference. Vol. 13, 2012.

17. Topi, H., Valacich, J., Kaiser, K., Nunamaker, J., Sipior, J., de Vreede, G. \& Wright, R. (2010), IS 2010: Curriculum Guidelines for Undergraduate Degree Programs in Information Systems. ACM and AIS, New York, NY and Park Ridge, IL.

18. Zweig, P. (2006). The Information Technology Workforce: Trends and Implications 2005-2008. MIS Quarterly Executive. 5(2), 47-53. 